\title{
Spirit Pluralisme dalam Klenteng Sam Po Kong Semarang
}

\author{
Edi Nurwahyu Julianto \\ (glowedy@gmail.com) \\ (Dosen Ilmu Komunikasi FTIK USM)
}

\begin{abstract}
Abstrak
Klenteng Sam Po Kong has very deep meaning as a symbol of multi cultural; multi ethnic nd multi religious. Klenteng Sam Po Kong has a different function, not only used by people with background religious Tri Dharma (budha, Tao and Konghuchu), but also used by Javanese ethnic with different religious backgrounds. Between ethnic China and Java, mutual respect and tolerance run beliefs and rituals of each. More over, Klenteng Sam Po Kong is a form of pluralism which reflected the fact Sino Javanese Muslim Culture is preserved to date both of sightings physical culture and system cultural in the form of religios rites peerformed by ethnic china and java.
\end{abstract}

Kata Kunci : Pluralisme, Klenteng Sam Po Kong, Kerukunan

\section{PENDAHULUAN}

Pluralisme dalam setiap aspek kehidupan bermasyarakat, berbangsa dan bernegara merupakan sesuatu yang tidak bisa ditolak keberadaannya di Indonesia. Hal ini telah dirumuskan dalam slogan "Bhineka Tunggal Ika" yang kurang lebih bermakna bermacam-macam budaya tetapi membentuk satu bangsa dan satu negara, yaitu Bangsa Indonesia.

Konsep tentang plural society pada mulanya diperkenalkan oleh Furnivall, dimana bahwa ciri utama masyarakat majemuk adalah kehidupan masyarakat berkelompok yang berdampingan secara fisik, tetapi terpisah oleh perbedaan sosial dan tidak tergabung dalam sebuah satuan politik (Tunjung W Sutirto, 2003 : 48-49). Terkait dengan pluralitas atau kemajemukan masyarakat terdapat dua macam watak pluralitas yang saling bertolak belakang. Pertama, pluralitas bisa menjadi kekuatan besar untuk diarahkan kepada kesejahteraan bersama. Kedua, pluralitas bisa mengandung kerawanan kalau masing-masing tidak menyadari tujuan bersama. Sebagai contoh yang dialami oleh bangsa Indonesia, masyarakat dihadapkan pada masalah yang mengkhawatirkan, yaitu konflik kesukubangsaan, agama, pelapisan masyarakat yang mulai menggejala dan semakin besar frekuensinya.

Dalam perjalanannya sebagai suatu bangsa yang pluralistik, sejarah bangsa Indonesia banyak diwarnai dengan konflik antar suku maupun antar agama. Salah satu bentuk konflik yang tak kunjung teratasi dalam agenda integrasi nasional bangsa Indonesia adalah konflik anti etnis Cina. Sebagai bagian dari warga negara Indonesia, etnis Cina mempunyai nasib yang tidak begitu menguntungkan dibandingkan etnis-etnis lain yang hidup di Indonesia. Sejak keberadaannya di bumi Nusantara, etnis Cina atau lazim disebut warga tionghoa telah menimbulkan berbagai polemik.

Sentimen rasisme terhadap etnis Cina masih dilakukan oleh rezim Orde Baru sejak mereka mulai berkuasa diakhir dekade 1960-an. Pada tahun 1967 rezim Orde Baru mengeluarkan Instruksi Presiden Nomor 14 Tahun 1967 yang melarang perayaan pesta agama dan adat istiadat Cina. Begitulah, selama 32 tahun identitas kecinaan menjadi sesuatu yang tabu untuk ditunjukkan. Eksistensi masyarakat Cina semakin diakui setelah Presiden Abdurrahman Wahid 
mengeluarkan Keputusan Presiden Nomor 6 Tahun 2000 tentang pencabutan Inpres No 14 Tahun 1967. Pengakuan bahwa masyarakat Cina adalah bagian dari bangsa ini sepertinya menjadi sempurna setelah Presiden Megawati Soekarnoputri menetapkan Hari Raya Imlek dalam daftar tanggal merah almanak Indonesia. Warga Cina di Indonesia mulai dapat menampilkan jati dirinya secara terbuka, baik dalam kehidupan sehari-hari maupun tradisi kebudayaannya. Berlahan-lahan tradisi dan kebudayaan Cina mulai dikenal oleh masyarakat luas.

Bila kita menengok kebelakang, Interaksi masyarakat Nusantara, khususnya Jawa dengan bangsa Cina terjadi sejak awal abad pertama Masehi. Dalam perjalanan sejarah, interaksi yang berlangsung selama berabad-abad ini melibatkan sejumlah budaya Cina yang meresap dalam kehidupan sehari-hari orang Jawa. Tak pelak, masyarakat Cina memainkan peran yang sangat penting dalam perkembangan budaya di Jawa. Ini dibuktikan pada bentangan abad ke 15-16 telah terjalin apa yang disebut sebagai Sino Javanese Muslim Culture sebagai bentuk akulturasi kebudayaan Cina, Jawa dan Islam.

Fakta adanya Sino Javanese Muslim Culture telah menunjukan bahwa komunitas Cina di negeri ini pernah hidup berdampingan secara damai dengan etnis lain, yaitu Jawa. Hingga kini kerukunan dan simbol-simbol Sino Javanese Muslim Culture masih terpelihara di Semarang, tepatnya di Klenteng Sam Po Kong. Klenteng yang terletak di daerah Gedong Batu, Simongan Kota Semarang ini mempunyai makna yang sangat dalam sebagai simbol multi kultural, multi etnis dan multi agama dengan adanya penampakan simbol-simbol berbagai agama dan etnis dalam setiap sudut bangunan kompleks dan ritual-ritual yang ada menyiratkan semangat kerukunan. Banyak orang yang berasal dari beragam latar belakang agama dan etnis datang ke
Gedung Batu untuk melakukan pemujaan di kompleks klenteng Sam Po Kong.

\section{Pembahasaan \\ Spirit Pluralisme Dalam Klenteng Sam Po Kong}

Salah satu kekayaan bangsa Indonesia adalah pluralisme budaya yang dimilikinya. Keanekaragaman etnis dan agama terbentang dari sabang sampai merauke. Kata Pluralisme berasal dari bahasa inggris, yaitu Suatu kerangka interaksi, dimana setiap kelompok menampilkan rasa hormat dan toleran satu sama lain, berinteraksi tanpa konflik atau asimilasi Menurut Direktur Eksekutif International Centre for Islam and Pluralism (ICIP), M Syafi'i Anwar. Menurut Syafi'I, Pluralisme itu mengakui keberagamaan orang lain, tanpa harus setuju. Selain itu, yang terpenting, bukan sekadar menjadi toleran, melainkan menghormati ajaran agama orang lain. Dan sadar betul bahwa keberagamaan orang lain itu bagian yang sangat fundamental dan inheren dengan hak asasi manusia. Konsep pluralisme tidak sekadar toleransi, tetapi lebih menuju kepada penghormatan kepada yang lain (Meneguhkan Pluralisme untuk Memperkokoh Persaudaraan, AtTanwir - Pencerahan - Enlightenment Aufklarung.htm).

Kemajemukan budaya Indonesia menjadi lebih komplek karena adanya sejumlah etnis asing yang hidup didalamnya memberikan kontribusinya dalam menambah khasanah budaya nasional. Salah satunya adalah etnis Cina, dimana pada bentangan abad 15 dan 16 memberikan sub kebudayaan baru bagi Indonesia, yaitu Sino Javanese Muslim Culture. Mulai dari bahasa, pakaian, arsitektur, makanan dan kesenian dihasilkan oleh keintiman ketiga unsur tersebut (Cina Jawa Islam). Sebagai contoh dari akulturasi kebudayaan Cina Jawa dan Islam adalah : Ukiran padas di masjid kuno Mantingan-Jepara, menara masjid pecinaan Banten, konstruksi pintu makam 
Sunan Giri di Gresik, arsitektur keraton Cirebon beserta taman Sunyaragi, konstruksi masjid Demak --terutama soko tatal penyangga masjid beserta lambang kura-kura, konstruksi masjid Sekayu di Semarang dan sebagainya, semuanya menunjukkan pengaruh budaya Cina yang cukup kuat. Bukti lain dapat ditambah dari dua bangunan masjid yang berdiri megah di Jakarta, yakni masjid Kali Angke yang dihubungkan dengan Gouw Tjay dan Masjid Kebun Jeruk yang didirikan oleh Tamien Dosol Seeng dan Nyonya Cai. Sayang fenomena Sino Javanese Muslim Culture tidak terpelihara dengan baik, bahkan oleh masyarakat Tionghoa muslim sendiri. Banyak dari mereka yang tidak mengerti mengenai asalusul/genealogi mereka. Para sejarawan Tanah Air juga sangat langka yang merawat atau memelihara kesejarahan akulturasi Tionghoa, Islam, Jawa ini. Mereka umumnya terkena penyakit intellectual laziesness atau kemalasan intelektual untuk melakukan penggalian sejarah yang memang minim dokumentasi tertulis ini (Sumanto Al Qurtuby, Cheng Ho, Islam, dan Indonesia, Grup Google soc_culture_indonesia.htm).

Kendati demikian, Fakta adanya Sino Javanese Muslim Culture sebagai bentuk pluralisme kebudayaan ini masih dapat dilihat dalam Klenteng Sam Po Kong di Gedung Batu Simongan Semarang. Pluralisme yang ada tidak hanya ditunjukan dalam unsur-unsur kebudayaan fisik saja. Lebih dari itu, simbol kebudayaan yang berupa sistem budaya, seperti ritual masih terpelihara hingga kini.

\section{Simbol Cina Dalam Klenteng Sam Po Kong.}

Dominasi penampakan simbol Cina hampir menghiasi pada sudut bangunan kompleks Klenteng Sam Po Kong. Hal ini wajar terjadi karena rombongan ekspedisi Cheng Ho berasal dari daratan Cina dan sekarang-pun dikelola oleh orang Cina, sekalipun tidak seiman dengan Laksamana Cheng Ho. Simbol Cina tampak dari bentuk bangunan, ritual dan upacara serta ornamen yang ada di Klenteng Sam Po Kong., diantaranya lampion, lilin, hio, patung dewa-dewa serta dominasi warna warna sakral Cina, yaitu merah dan kuning yang membungkus tembok serta pernakpernik yang ada. Warna merah menggambarkan kegembiraan, artinya manusia hidup didunia harus selalu optimis, sedangkan kuning adalah warna kekaisaran dan sebagai lambang unsur tanah yang melambangkan kesejahteraan hidup di dunia. Sementara Klenteng Sam Po Kong memiliki gaya arsitektur bangunan khas Cina, dengan ornamen dan atap melengkung naik yang menunjukkan gaya Tiongkok Selatan.

Unsur dominan yang ada di kompleks Klenteng Sam Po Kong adalah altar penyembahan untuk Tian atau Tuhan, disamping juga adanya altar pemujaan untuk dewa pintu serta dewa atau orang suci di masing-masing kompleks klenteng. Altar pemujaan tersebut merupakan altar khas yang ada disetiap bangunan pemujaan yang bernafaskan konghucu. Altar merupakan perantara setiap pengunjung untuk berhubungan dengan dewa-dewi sekaligus menyampaikan segala permohonannya.

Sementara ritual-ritual yang dilakukan oleh etnis Cina yang beribadah di sini juga bernafaskan kebudayaan Cina. Ini tampak dari cara berdoa mereka yang menggunakan hio sebagai perantara serta perayaan-perayaan yang diadakan oleh mereka. Perayaan yang terbesar dilakukan oleh pihak klenteng adalah Sembahyang Sam Po Gia Hio, yaitu sembayang untuk menghormati kedatangan Sam Po Kong di Semarang yang dilaksanakan setiap tanggal 15 Lak Gwee, penanggalan Imlek.

\footnotetext{
Simbol Jawa Dalam Klenteng Sam Po Kong.
} 
Penampakan simbol jawa lebih terlihat dari kegiatan ritual (baik perseorangan maupun rombongan) yang seringkali dilaksanakan di kompleks klenteng ini. Kegiatan ritual tersebut adalah ziarah makam. Objek material simbol jawa ditunjukan dengan tempat sesaji serta ritual pembakaran kemenyan dan bunga yang dilakukan di makam Kyai Juru Mudi Dampo Awang, makam Kyai dan Nyai Tumpeng dan ruang persembahayangan Kyai Jangkar . Terkadang juru kunci yang terdapat pada ketiga tempat tersebut juga menggunakan doa dan matera berbahasa jawa dalam menyampaikan permohonan pengunjung. Bentuk atap ruangan makam Kyai dan Nyai Tumpeng adalah bergaya joglo menunjukan simbol rumah adat jawa.

\section{Simbol Islam Dalam Klenteng Sam Po Kong.}

Penampakan simbol Islam terdapat pada bangunan makam Kyai Juru Mudi Dampo Awang dimana bentuk makam dengan cungkup menonjol dikedua ujungnya merupakan ciri khas makam Islam. Sedangkan keberadaan makam Kyai dan Nyai Tumpeng merupakan makam Islam, sekalipun dari penampakan fisik tidak menjurus kepada bentuk makam Islam. Namun, simbol Islam ditampakan pada sebutan 'Kyai" dan 'Nyai" yang mengacu pada sebutan orang yang dihormati dan disegani dalam tatanan masyarakat Islam. Selain itu penampakan simbol islam diwujudkan dalam doa-doa yang digunakan baik peziarah yang beragama Islam maupun oleh juru kunci pada makam Kyai Juru Mudi Dampo Awang, makam Kyai dan Nyai Tumpeng serta makam Kyai Jangkar.

\section{Spirit Kerukunan Dalam Klenteng Sam Po Kong}

Berbeda dengan klenteng-klenteng yang telah ada di Semarang atau bahkan di tempat lainnya, Klenteng Sam Po Kong mempunyai fungsi ibadah yang lain dari biasanya. Bila Klenteng identik sebagai tempat ibadah umat Tri darma (Tao, Budha dan Konghucu), Klenteng Sam Po Kong juga digunakan untuk beribadat bagi etnis Jawa dengan latar agama yang berbeda. Di Klenteng inilah kerukunan umat beragama terpelihara dengan baik. Mereka yang datang di Klenteng Sam Po Kong tanpa merasa risih masuk kedalam klenteng untuk menjalankan ritual sesuai dengan kepercayaan mereka masingmasing tanpa mereka harus berpindah agama. Kerukunan yang terjadi di dalam Klenteng Sam Po Kong tercermin dari sikap toleransi diantara mereka yang saling menghargai untuk menjalankan ritualnya masing-masing. Bahkan kerukunan ini sudah tercipta sejak Klenteng ini berdiri. Disini secara tidak sengaja telah terjadi pembauran antara etnis keturunan Cina dan Jawa yang terjalin harmonis, sehingga Klenteng Sam Po Kong mempunyai fungsi bagi kedua etnis tersebut.

Bagi etnis Cina yang beragama Konghucu bentuk persembahayangan tidak dilakukan setiap hari, melainkan disesuaikan dengan kebutuhan mereka. Hanya saja setiap tanggal 1 dan 15 penanggalan Imlek, mereka diwajibkan untuk melakukan ritual doa di klenteng. Ritual doa ini dimulai dengan menyalakan lilin sebagai lambang penerang. Setelah ketiga hio akan disulut kedalam cawan api untuk kemudian ditancapkan ke altar penyembahan sambil berdoa. Tiga hio yang digunakan mewakili bumi (tanah), air dan udara. Penggunaan hio dimaksudkan sebagai perantara supaya doa-doa yang dipanjatkan dapat segera naik ke atas (langit), sehingga didengar oleh Tian (Tuhan) dan Dewa-dewi yang mereka sembah. Tata cara berdoa dimulai dari altar penyembahan kepada Tian yang selalu berada dibagian depan bangunan klenteng. Kemudian dilanjutkan dengan menyalakan hio pada altar dewa pintu, bila ada, karena tidak semua klenteng mendirikan altar persembahayangan untuk dewa pintu. Selanjutnya, mereka baru melakukan persembahayangan pada altar untuk dewa-dewi yang ada di klenteng. 
Setiap klenteng memiliki dewa-dewi yang berbeda-beda. Selain ritual tersebut, biasanya banyak dari masyarakat yang mencoba keberuntungan mereka melalui ramalan yang dibimbing oleh Biokong (sebutan untuk juru kunci klenteng). Adapun Cara meramal keberuntungan mereka dilakukan melalui tabung bambu yang berisi beberapa puluh tusuk "pociam" yang masing-masing sudah tertera angka. Pemohon ataupun dapat melalui Biokong akan mengkocok tabung bambu tersebut. Tusuk yang keluar akan memperlihatkan angka yang kemudian akan dicocokkan dengan selembar kertas yang bertuliskan tentang ramalan yang sesuai dengan nomor yang tertera di tusuk bamboo tersebut. Selain cara itu, untuk mengetahui peruntungan dapat dilakukan melalui melempar "peiciao" atau mata uang logam khusus. Apabila peiciao tersebut dilempar dan jatuhnya berlainan arah (berbeda permukaan), berarti permohonan diterima. Tetapi jika dilempar dan jatuhnya pada permukaan yang sama, maka harus diulangi lagi sampai permukaannya berbeda.

Di klenteng Sam Po Kong terdapat beberapa kompleks yang biasanya dikunjungi oleh etnis Cina, yaitu Tempat pemujaan Sam Po Tay Djien, Tempat pemujaan Dewa Bumi, altar pemujaan kepada nabi-nabi Konghucu dan roh-roh umum (Hoa Peng). Disamping itu mereka juga melakukan ritual doa di makam Kyai Juru Mudi Dampo Awang, Ruang Pemujaan Kyai Jangkar serta Makam Kyai dan Nyai Tumpeng dan Kyai Tjundrek Bumi.

Sementara itu, setiap malam Jum'at kliwon, Klenteng Sam Po Kong banyak dikunjungi oleh pribumi, yang mayoritas beretnis Jawa. Ditempat yang dianggap keramat ini, peziarah Jawa biasanya meminta berkah yang bersifat keduniawian, seperti masalah ekonomi, kesehatan maupun keselamatan hidup. Banyak dari peziarah pribumi yang berprofesi sebagai petani dan pedagang ini sangat percaya bahwa dengan meminta pertolongan kepada kekuatan yang ada di kompleks klenteng dapat memberikan pengaruh terhadap rezeki yang akan mereka terima di masa datang. Dagangan mereka semakin laris, begitu juga dengan hasil panen menjadi lancar dan banyak. Para peziarah pribumi ini banyak melakukan ritual ziarah makam di beberapa tempat pemujaan yang ada di klenteng Sam Po Kong. Tempat pemujaan tersebut justru bukan di bangunan utama, melainkan di kompleks sekitarnya, yaitu Makam Kyai Juru Mudi Dampo Awang, Ruang Pemujaan Kyai Jangkar serta Makam Kyai dan Nyai Tumpeng dan Kyai Tjundrek Bumi.

Tata cara berdoa pada peziarah jawa yang mayoritas beragama islam ini tidak banyak memerlukan ritual yang kompleks. Syarat utamanya cukup membawa kembang setaman yang nantinya diberikan kepada Juru kunci sambil mengatakan apa yang diinginkannya (rezeki, keselamatan, jodoh dan sebagainya). Selanjutnya juru kunci akan melakukan ritual doa dengan membaca beberapa doa bernafaskan islam sambil membakar kembang setaman di tungku pembakaran yang ada di hadapannya. Ritual pun berakhir dengan juru kunci memberikan kembang yang dibungkus dalam kertas kecil untuk kemudian disimpan oleh pengunjung.

Sementara bagi para peziarah jawa yang ingin berdoa di klenteng utama, tempat pemujaan Sam Po Tay Djien ataupun Dewa Bumi, kembang setaman ini diganti dengan hio yang diberikan kepada biokong (juru kunci). Melalui biokong lah, hio yang jumlahnya 3 ini setelah disulut api akan disematkan dalam altar pemujaan sambil mengucapkan doa. Bahkan banyak pula setelah ritual ini selesai, peziarah jawa menyempatkan diri untuk mengetahui keberuntungan mereka dengan melempar puluhan tusuk "pociam". Setelah mengetahui peruntungannya, pemohon biasanya memberikan angpauw pada biokong, jumlahnya terserah pemohon. Selain ingin tahu peruntungan, ada juga 
peziarah yang datang supaya diberi kesembuhan dari penyakit yang dideritanya. Caranya adalah dengan meminta air yang sudah diberi doa oleh biokong. Air itu diperoleh dari sumber mata air yang mengalir di dalam gua tempat pemujaan Sam Po Tay Djien.

\section{Penutup}

Klenteng Sam Po Kong mempunyai makna yang sangat dalam sebagai simbol multi kultural, multi etnis dan multi agama. Berbeda dengan klenteng-klenteng pada umumnya, Klenteng Sam Po Kong yang berada di daerah Gedong Batu, Simongan Kota Semarang ini bisa dikatakan secara tidak sengaja terjadi pembauran antara 2 etnis, yaitu Cina dan Jawa. Klenteng yang lazimnya sebagai tempat sembahyang oleh umat Tri Dharma (Konghucu, Tao, dan Budha) ternyata juga banyak dikunjungi oleh masyarakat Jawa yang berasal dari beragam latar belakang agama tanpa salah satunya harus pindah agama. Hal ini terkait dengan sejarah Ekspedisi Cheng Ho ke 'Samudera Barat' pada tahun 1405-1433 dalam misi dagang dan politik pada masa kaisar ketiga Dinasti Ming, Zhu Di. Armada Cheng Ho dipercaya singgah di Semarang, yaitu di Simongan. Sosok Cheng Ho yang diyakini beragama Islam oleh etnis Cina maupun Jawa atas jasajasanya dihormati sampai saat ini.

Bagi etnis Cina, klenteng Sam Po Kong berfungsi sebagaimana mestinya yaitu sebagai tempat mereka berdoa juga bersembahyang dengan segala upacara khasnya. Sementara bagi masyarakat Jawa, apa yang ada di dalam klenteng dipercaya kekuatannya dapat memberikan berkah dalam menjalani kehidupannya. Ditempat yang dianggap keramat ini, peziarah Jawa biasanya meminta hal-hal yang bersifat keduniawian terutama dalam hal ekonomi, meskipun ada juga yang memohon hal-hal yang bersifat keselamatan. Di sinilah semangat kerukunan umat beragama telah terbangun sejak berdirinya klenteng Sam Po Kong. Masing-masing orang dengan latar belakang agama dan etnis yang berbeda satu sama lain saling menghormati dan bertoleransi dalam menjalankan kepercayaan dan ritualnya masing-masing. Walaupun ada sebagian orang yang melakukan penggabungan ritual antara kebudayaan Cina dan Jawa. Ini terlihat dalam bentuk ritual yang dilakukan orang Jawa yang ingin berdoa di klenteng Utama ataupun Ruang Pemujaan Dewa Bumi, bunga setaman dan sesaji yang biasa digunakan oleh masyarakat Jawa telah diganti dengan penggunaan dupa atau hio mengikuti tradisi berdoa masyarakat Cina.

\section{Daftar Pustaka}

Meneguhkan Pluralisme untuk Memperkokoh Persaudaraan, AtTanwir - Pencerahan Enlightenment - Aufklarung.htm

Sumanto Al Qurtuby, Cheng Ho, Islam, dan Indonesia, Grup Google soc_culture_indonesia.html

Tundjung W Sutirto, Kemajemukan dan Adaptasi Budaya Antar Etnik (Studi Kasus di Kota Surakarta) dalam buku Agama, Kebudayaan dan Pendidikan (Sejumlah Pemikiran), Perhimpunan Citra Kasih, 2003. 